\title{
Cuidando das famílias: uma tarefa de psicólogos e psiquiatras no IPUB/UFRJ
}

\section{Providing care to families: a task for psychologists and psychiatrists at IPUB/UFRJ}

\author{
Edna Lúcia Tinoco Ponciano ${ }^{1}$, Maria Tavares Cavalcanti², Terezinha Féres-Carneiro ${ }^{3}$
}

${ }^{1}$ Doutora. Pesquisadora, Fundação de Amparo à Pesquisa do Estado do Rio de Janeiro (FAPERJ), Rio de Janeiro, RJ. Pontifícia Universidade Católica do Rio de Janeiro (PUC-Rio), Rio de Janeiro, RJ. ${ }^{2}$ Doutora. Professora adjunta, Instituto de Psiquiatria (IPUB), Universidade Federal do Rio de Janeiro (UFRJ), Rio de Janeiro, RJ. ${ }^{3}$ Pós-Doutorado. Professora titular, Departamento de Psicologia, PUC-Rio.

\section{Resumo}

Introdução: A família é um foco de observação e de intervenção, não somente para terapeutas de família, mas para todos que lidam com o paciente psiquiátrico. Em nossa pesquisa, realizada em 2005/2006, no Instituto de Psiquiatria da Universidade Federal do Rio de Janeiro, investigamos as diversas formas como psicólogos e psiquiatras estão em contato com as famílias. Para além da especificidade profissional e das dificuldades apresentadas, nosso objetivo é o de oferecer maior visibilidade à presença da família, destacando a experiência desses profissionais.

Método: Adotamos uma metodologia qualitativa, realizando entrevistas individuais.

Resultados e Conclusão: Os dados das entrevistas com 15 profissionais sugerem que os entrevistados, apesar dos obstáculos, mantêm contatos com as famílias dos seus pacientes. A sistematização dos diversos contatos torna-se necessária, a fim de que seja estabelecida uma rotina de assistência à família e sejam viabilizadas pesquisas que demonstrem a eficácia das propostas de intervenção.

Descritores: Família, hospital psiquiátrico, intervenção.

\begin{abstract}
Introduction: The family is a focus for observation and intervention not only for family therapists but for all those dealing with the psychiatric patient. During our study carried out at the Institute of Psychiatry of Universidade Federal do Rio de Janeiro (2005-2006), we investigated the several methods used by psychologists and psychiatrists to work with the families. In addition to showing the specific professional approaches and some other difficulties, we aim at increasing the visibility of the family, highlighting the experience of these professionals

Methods: We used a qualitative methodology by means of individual interviews.

Results and Conclusion: Data from the 15 interviews suggest that, despite the obstacles, the interviewed professionals keep contact with the patient's families. Systematization of the several methods of contact is necessary so that family assistance can be provided on a regular basis and studies that show the effectiveness of the intervention proposals can be enabled.
\end{abstract}

Keywords: Family, psychiatric hospital, intervention.

\section{Correspondência:}

Edna Ponciano, Rua Miranda Valverde, 118/202, Botafogo, CEP 22281-000, Rio de Janeiro, RJ. Tel.: (21) 2527.1870, (21) 9978.7568. E-mail: ponciano@uol.com.br Não há conflitos de interesse associados à publicação deste artigo. 


\section{Introdução}

No campo da saúde mental, a família começou a se tornar foco de interesse e pesquisa durante os anos 50, principalmente nos EUA, difundindo-se por diversos países, até os dias atuais. Exemplos clássicos do início dessas pesquisas são o grupo de Palo Alto, na Califórnia, dirigido por Gregory Bateson ${ }^{1,2}$, e o estudo realizado por Laing \& Esterson ${ }^{3}$, na Inglaterra. Constatada a importância de abordar a família, ao longo do tempo, surgem propostas terapêuticas ligadas aos mais variados diagnósticos psiquiátricos ${ }^{4-10}$. Dessa forma, procura-se orientar a família para lidar com a doença mental, não somente a partir do diagnóstico do paciente identificado e da especificidade de seu tratamento, mas incluindo também a relação entre os membros da família, tornando-se parte de uma proposta de assistência ao paciente psiquiátrico.

No contexto do Instituto de Psiquiatria (IPUB) da Universidade Federal do Rio de Janeiro (UFRJ), a partir de diversas modalidades, o atendimento a famílias se faz presente. Cotidianamente, a família é um foco de observação e de intervenção, não somente para terapeutas de família, mas para todos aqueles que lidam com o paciente psiquiátrico, desde sua entrada até a alta.

No IPUB, desde o final da década de 70, há um curso de especialização em terapia de família ${ }^{11}$, o que caracteriza maior sistematização dos atendimentos, dirigidos aos familiares. A proposta desse curso coincide com o início do movimento da reforma psiquiátrica no Brasil, que defende a ideia de que o doente mental deve deixar a instituição asilar e retornar à sua comunidade $^{12}$. $\mathrm{O}$ início do atendimento à família, portanto, ocorre ao mesmo tempo em que há uma transformação da proposta de assistência psiquiátrica.

Na década de 90, observa-se a presença de usuários e de familiares na reforma psiquiátrica, que participam ativamente da formulação de novas práticas de saúde mental ${ }^{13}$. A família torna-se uma parceira no processo de reabilitação psicossocial. Diante das curtas permanências nas enfermarias e da situação de alta hospitalar, a família é vista como um recurso a ser trabalhado, além de ocupar um lugar importante no tratamento e na recuperação do paciente psiquiátrico. Com os novos serviços, deve ser assegurado o direito do usuário a usufruir de um refúgio nos períodos de sofrimento psíquico e o direito da família à participação ativa no tratamento ${ }^{14}$. Diante desse contexto, ressaltamos a importância de pesquisas que busquem contribuir para a implementação da lei 10.216/01, evidenciando a importância da participação da família e da sociedade na assistência ao paciente com transtorno mental e indicando caminhos para a sua reinserção social.

Apesar do pioneirismo do IPUB/UFRJ, há uma carência de pesquisas e de sistematização de tais práticas. Mesmo que tenha sido destacada a importância da participação da família, ainda há muito a se investigar sobre as intervenções realizadas em uma instituição psiquiátrica. Para tanto, o primeiro passo é reconhecer a ligação entre o contexto relacional, a saúde mental e os resultados clínicos obtidos a partir dessa perspectiva. Desse modo, podem ser sistematizadas as rotinas de atendimento que incluem a família e que não são exclusivamente realizadas por terapeutas de família.

É preciso, portanto, reconhecer que as relações familiares e os eventos ocorridos no interior da família são relevantes para a compreensão do desenvolvimento e da manutenção da psicopatologia. Considerações práticas ditam a necessidade de se dar maior atenção às relações familiares, porque a família é, frequentemente, a primeira fonte de suporte e de influência, tornando-a parte essencial de intervenção clínica ${ }^{15-}$ ${ }^{17}$. Além disso, os problemas mentais em um dos membros têm impacto direto sobre o bem-estar emocional dos outros membros da família ${ }^{18}$.

A despeito da relevância das relações familiares, muitos profissionais conhecem vagamente a proposta teórica de inclusão da família no tratamento psiquiátrico ou, mesmo quando reconhecem a importância de incluí-la, possuem dúvidas quanto à indicação e à definição do encaminhamento pertinente. Desse modo, no dia-a-dia desenvolvem uma abordagem da família que ainda não encontrou respaldo em sua formação teórico-técnica. A lacuna encontrada na formação vai sendo preenchida com a experiência de estar em uma instituição psiquiátrica em constantes contatos com os familiares. É preciso, porém, oferecer maior respaldo às intervenções que vêm ocorrendo, ao tornar acessível uma discussão que relaciona família e transtorno psiquiátrico.

Em nossa pesquisa, realizada durante os anos de 2005 e 2006, destacamos o modo como psicólogos e psiquiatras vêm realizando o contato com as famílias de seus pacientes. Ainda que não possuam uma perspectiva teórica a respeito da conexão entre processos relacionais/familiares e a saúde mental, os profissionais entrevistados formulam a necessidade de trabalhar com as famílias a partir do contato que realizam durante o processo de um tratamento individual.

Por razões variadas, não é incomum que os psicólogos tenham contato com diferentes membros das famílias de seus pacientes, em diversos momentos e ao longo do tratamento. Embora não haja uma formação adequada e pouco se tenha escrito sobre o tema, os psicólogos necessitam fazer algum tipo de contato com os familiares ${ }^{19}$. Guardadas as diferenças entre os profissionais, os psiquiatras, igualmente, necessitam estar em contato com as famílias e, para tal tarefa, também não possuem uma formação adequada, enfrentando variados obstáculos devido à rotina institucional e à premência de atenderem as necessidades de seus pacientes individuais ${ }^{20}$.

Para além da especificidade profissional e das dificuldades apresentadas, nosso objetivo é o de oferecer maior visibilidade à presença da família, destacando a experiência dos psicólogos e dos psiquiatras do IPUB/UFRJ. Desse modo, a partir da observação de que a família está presente em todos os serviços do IPUB/UFRJ, uma pergunta se destaca: que tipos de contatos existem entre os profissionais e as famílias? Muitos desses contatos são informais, ocorrem no dia-a-dia, não são sistematizados, não têm um objetivo específico e são vivenciados com muita ansiedade ${ }^{21}$. Na pesquisa realizada, 
investigamos esses contatos cotidianos, entrevistando psicólogos e psiquiatras. Procuramos conhecer como são os contatos, quais são as dificuldades, quais os resultados e quais são as demandas produzidas.

\section{Metodologia}

Procurando abranger os vários setores do IPUB, incluindo o plantão psiquiátrico, os ambulatórios e as enfermarias, foram entrevistados 15 profissionais, sendo seis residentes em Psiquiatria (R), quatro médicos psiquiatras (M) e cinco psicó$\operatorname{logos}(\mathrm{P})$, alunos dos cursos de especialização do IPUB. Privilegiamos os profissionais que têm uma abordagem individual do paciente psiquiátrico, a fim de conhecer como eles inserem a família em um tratamento que se orienta exclusivamente ao indivíduo. Profissionais como enfermeiros, assistentes sociais e terapeutas de família, com diversas formações, lidam diretamente com a família do paciente, parecendo-nos que têm um contato mais contínuo. Por esse motivo, buscamos a perspectiva dos médicos e dos psicólogos, com a intenção de conhecer o modo como estão em contato com os familiares, apesar de não terem uma formação para tanto.

Organizadas a partir de um roteiro semiestruturado, as entrevistas, realizadas pela primeira autora, ocorreram na instituição de acordo com a disponibilidade de cada profissional. Todas as entrevistas foram gravadas com a permissão dos entrevistados, sendo preservado o anonimato. Todos os entrevistados assinaram um termo de consentimento, no qual declararam aceitar a participação na pesquisa informada. Para testar e avaliar o roteiro da entrevista, foram realizadas duas entrevistas-piloto, sendo ambas aproveitadas em nossa análise. Consequentemente, o roteiro foi confirmado e não sofreu nenhuma alteração.

Utilizamos uma metodologia qualitativa, submetendo as entrevistas à análise de conteúdo ${ }^{22}$, após a transcrição. Assim, destacamos fragmentos do discurso dos entrevistados, agrupando as respostas de acordo com as seguintes temáticas, que caracterizam núcleos de sentido: contatos com a família, objetivos para os contatos, resultados, barreiras, vantagens, necessidade de cuidar da família e os encaminhamentos realizados. As falas dos entrevistados retratam o cotidiano e as diversas situações características do hospital psiquiátrico, revelando a presença da família, a necessidade do cuidado e de estar em contato com ela.

Esta pesquisa foi aprovada pelo Comitê de Ética do IPUB/UFRJ. Todos os entrevistados forneceram consentimento informado por escrito.

\section{Resultados e discussão}

\section{Contatos com a família}

Antes de sistematizar um tratamento específico, é preciso responder à questão de quando o contato com a família é realizado, procurando, de acordo com as práticas dos profissionais, adequar a construção de um serviço que inclua os familiares. Os entrevistados relatam, inicialmente, duas situações quando ocorre o contato: devido à gravidade do caso e ao tempo de permanência na instituição psiquiátrica, que, quanto mais longo for, promove a destituição da família, avaliando-a como inapta para lidar com o membro doente.

É um paciente muito grave, esquizofrênico (...) uma situação que a família lida com dificuldade. Todo final da consulta eu atendo eles também. (R1)

Os pacientes lá da enfermaria de longa permanência (...) a gente está fazendo um esforço muito grande de retomar o contato com as famílias. (M1)

Quando o caso é grave, é importante chamar a família para comparecer à instituição, até mesmo para pacientes adultos. Já no atendimento à criança e ao adolescente, a presença da família é constante, tornando o contato muito frequente. No entanto, tal proximidade é vista como arriscada. O profissional deve estar atento para efetuar o encaminhamento da família para outros espaços, independentes do tratamento do seu membro doente.

No caso, este adolescente que eu atendo... eu estou sempre com a mãe para estar vendo, coletando algumas questões e vendo como ele está. Eu a encaminhei para um outro tipo de atendimento psicoterápico, para não confundir o espaço que é só dele, para ela não trazer algumas questões que eram dela. (P5)

Além da gravidade, o entrevistado a seguir ressalta a importância de se aproveitar a presença da família, principalmente quando ocorre o primeiro atendimento.

Quando o paciente vem pela primeira vez, normalmente ele vem acompanhado. (...) a gente aproveita para fazer a primeira entrevista junto com o familiar, e alguns passam a vir nos atendimentos posteriores. (M4)

No plantão psiquiátrico e na enfermaria, a família busca ajuda para lidar com as situações de crise. Com o tempo, porém, a família torna-se distante, acomodando-se e desqualificandose. As situações de emergência são caracterizadas como as que têm a maior presença da família e, consequentemente, é quando o contato com os profissionais costuma ocorrer.

No plantão, eu tenho contato constantemente. (...) é como se a família pudesse dar as informações sobre o paciente e depois a gente faz alguma coisa com o paciente, meio mágica, para devolver ele. (R2)

Durante a internação, destacam-se dois momentos quando a família costuma ser chamada. $\mathrm{O}$ primeiro diz respeito à necessidade de que os profissionais têm de conhecer mais a história de 
seus pacientes, no início da internação. O segundo ocorre quando há alta e o paciente deve retornar aos seus familiares. São dois momentos estanques, não caracterizando encontros que seguem a uma rotina de atendimentos sistemáticos. Abusca dos profissionais pela família não costuma fazer com que ela se sinta parte integrante do processo de tratamento. De um lado, a família responsabiliza o hospital, isentando-se. De outro, o hospital afasta a família.

Acho que a gente chama muito a familia para conversar a história e depois... chama a familia para dar alta. Acho que se utiliza muito pouco a família no dia-a-dia. (M1)

É possível que ocorram encontros casuais no pátio do IPUB, caracterizando a busca da família pelo profissional. Nesse caso, o relato dos psicólogos reforça a necessidade de separar o atendimento do paciente e o dos familiares, tomando cuidado para não haver, entre os dois, uma mistura, vista como prejudicial.

Hoje encontrei com três famílias: uma mãe, que eu encaminhei para psicoterapia; uma esposa, que veio a umas duas sessões comigo e eu encaminhei para outra terapeuta; e uma mãe de uma paciente me ligou. (P1)

$\mathrm{Na}$ instituição psiquiátrica, são comuns as invasões ao atendimento, por parte dos familiares. Os psicólogos são os que parecem se preocupar mais com esse aspecto, embora isso também incomode aos psiquiatras.

Filha que chega com a mãe e a mãe quer entrar antes da filha para ver o que está acontecendo, para invadir o espaço de tratamento da filha. (P4)

Os psicólogos também ressaltam que é importante estar em contato com a família nos momentos de maior dificuldade. Por exemplo, quando é necessário trazer o paciente de volta ao tratamento, procurando conhecer o modo como a família compreende esse processo.

No caso do atendimento dos meus pacientes, volta e meia eu falo com a mãe ou com o pai, em momentos de maiores dificuldades. (...) Justamente nesses momentos que o contato com a família é feito para ver como a gente pode estar trazendo esse paciente de volta para o tratamento, para saber como está essa família. (P2)

\section{Objetivos para os contatos}

Apesar de enfatizarem a necessidade do contato, os objetivos ainda não são utilizados como uma forma de sistematizar a assistência às famílias. De qualquer modo, eles permitem visualizar quais são os resultados obtidos.

De acordo com o relato dos entrevistados, especificamos, a seguir, os principais objetivos para se manter contato com as famílias.
- Obter a participação da família no tratamento:

(...) Uma paciente internada (...) e a mãe é que vai dando para gente a percepção dela, de que está melhor. Eu acho que ela vai percebendo que é capaz de lidar com aquilo. (...) deixar que ela participe, porque afinal é aquela pessoa que vai cuidar desse paciente depois. (M1)

- Conhecer a história do paciente, obtendo informações da família ao mesmo tempo em que a prepara e oferece orientação para lidar com diversas situações que envolvem o transtorno psiquiátrico:

Obter informações, dar alta e ter também um contato para preparar, ajudar a família a lidar com a situação. (M5)

Orientação, ajudar na medicação. (...) Se tiver a necessidade de uma internação, se a gente tem um bom vínculo com a família, fica mais fácil aceitar o procedimento. Para a família estar aceitando e concordando também, tendo confiança... (M3)

- Conhecer a dinâmica familiar e a percepção da família quanto ao transtorno psiquiátrico:

Basicamente de estar percebendo como é que esta familia funciona. (...) perceber como ele funciona a partir, por exemplo, da mãe, do pai ou da irmã. (P3)

Para conhecer a familia. (...) Eu acho que você tem que conhecer onde o paciente está inserido porque eu acho que faz toda a diferença. (R2)

- Compreender a gravidade do caso e a postura de distância da família:

Não tem culpa. Eu tento entender os dois lados (descreve a distância entre uma filha e a sua mãe doente). E aí, conhecendo a história, eu soube que essa paciente nem criou a filha. Essa filha foi criada pelos vizinhos. Essa filha não tem nenhum vínculo com a mãe e tem dois filhos pequenos, $e$ quando a paciente, a avó das crianças, descompensa, ela faz coisas como deixar o gás ligado. (...) Então, eu acho que a gente tem outra visão. Eu consigo ver que essa mãe não criou essa filha porque já era doente, enquanto a própria filha está no meio disso tudo, ela não consegue ver. (M2)

\section{Resultados dos contatos}

Os resultados do contato com as famílias não são animadores, porque as dificuldades ainda parecem ser maiores do que os benefícios. Mas, segundo os entrevistados, é importante que haja insistência. Apesar da dificuldade de alcançar bons resultados, a família é vista como necessária para o bom encaminhamento do tratamento psiquiátrico, de acordo com 
a perspectiva do próprio paciente. Além disso, ela auxilia na adesão ao tratamento, a partir das alianças feitas e da colaboração, adquiridas durante esses contatos.

Na maioria dos casos, vincula mais. Acho que o paciente fica mais engajado. (P3)

De qualquer forma, estar em contato com a família faz com que ela se sinta apoiada e facilita o tratamento, ainda que o resultado não seja tão relevante quanto se gostaria.

A curto prazo, você não tem um resultado grande, não, mas eu acho que tem resultado. Acho até que a família se sente apoiada, pelo menos. A família sabe que tem você ali, se precisar. Sabe que você entende o que eles estão passando. Então, eu acho que, de alguma forma, deve modificar as coisas, sim. (M2)

\section{Barreiras}

Os entrevistados descrevem as principais barreiras para se manter contato com as famílias.

- A onipotência do terapeuta, que afasta a família:

Eu acho que isso é você pensar que vai poder, em termos de recursos terapêticos, esgotar e resolver o problema daquele paciente e não que o problema dele está inserido em uma estrutura familiar. Ou, então, você enxerga a família como alguém que não faz parte do arsenal terapêutico. (M1)

- A imprevisível mobilização de questões variadas, mexendo com a família de uma forma não suportada pelos familiares:

Dá uma estremecida, sim, e aí você vê que a família sai de cena e, dependendo do tipo de paciente, o paciente sai também porque estava muito motivado pela influência daquela família. (P4)

- Quando a família é prejudicial ao paciente, dificultando ou inviabilizando o contato. No primeiro exemplo, a interferência da esposa é vista como prejudicial, já que ameaçava o paciente dizendo que contaria um segredo aos filhos. $\mathrm{O}$ manejo do terapeuta, porém, permite que o paciente e seus filhos tenham um espaço terapêutico. No segundo exemplo, é destacada a inabilidade da família, prejudicando o processo de internação e de alta.

E ai ele resolveu, depois de estar na terapia, contar isso para os filhos. Então, o resultado foi completamente diferente do que a esposa imaginava que os filhos, no caso, tomariam partido contra ele; e ai não, os filhos acolheram e estão super engajados. Querem fazer terapia de família. (P5)
Quando a gente tem pacientes internados, a gente tem dificuldade de a família ter uma tolerância com o paciente. (...) Se a família tivesse um pouco mais de paciência e tolerância, seria possivel manter o paciente em casa. (R3)

Os psicólogos tendem a atribuir as barreiras às famílias. Já os psiquiatras tendem a avaliar a si mesmos e ao serviço como uma das principais barreiras.

- A família torna-se uma barreira quando questiona o resultado e/ou a necessidade do tratamento e de determinadas técnicas, interferindo e atrapalhando:

Vem se fazendo um trabalho dessa mãe estar vindo às reuniões de familia. Já se ligou várias vezes para essa mãe e a mãe nunca vem, e, quando vem, a mãe não deixa a filha falar. Enfim, há esse desencontro. Então, essa mãe, em vez de ajudar, ela acaba atrapalhando. (P4)

- A falta de suporte, tanto emocional quanto material, e a situação social da família são barreiras que, somadas, geram uma sobrecarga aos familiares e dificultam o contato:

Eu acho que é a falta de suporte para a família. Porque eu acho que a familia chega super desgastada e acaba que você tem pouco para oferecer para aquela família. Na prática, é dificil. (R2)

A familia tem problema de passagem (falta dinheiro para o transporte). Tem problemas reais. (M2)

- Quando a família responsabiliza o hospital pelos cuidados ao seu membro doente, o contato é um fator de desgaste na relação dos profissionais com os familiares:

Aqui dentro do IPUB, como residente, eu cansei de ver pacientes que tinham alta médica e os familiares não queriam buscar, não concordavam com a alta porque queriam que ele ficasse mais aqui, ou então problemas sociais graves que a família queria mais era abandonar mesmo. O paciente não tinha para onde ir. Então, queriam deixar o paciente internado aqui. (R6)

\section{Vantagens}

As vantagens de se manter contato com as famílias estão relacionadas ao cumprimento dos objetivos, acima descritos, e à busca de bons resultados para o tratamento, tal como descrito pelos entrevistados:

- A família representa uma necessidade para qualquer pessoa; estar em contato permite que não sejam desfeitos os laços do paciente:

A gente precisa de laços, sem os laços não seremos nós. Os laços são uma pequena parte da história da gente. É claro 
que se a gente deixa o paciente ter autonomia para escolher, ele vai voltar para a familia. O problema é se a gente isola o paciente da família, e com a internação isso acontece. (M1)

- Estar em contato é o que permite a formação de alianças, que conduzem à participação da família, levando a bons resultados no tratamento:

A família estar informada, não sobre o que acontece dentro das sessões, mas como está sendo o progresso desse paciente. A gente estar podendo trabalhar junto. (P4)

- Há uma mudança na percepção que os profissionais têm da família, ampliando a visão do tratamento:

Eu acho que é muito importante para o paciente. Porque eu acho assim que não adianta só botar remédio. (...) Tem muitos pacientes que eu acho que o problema é mais da família do que o remédio. (R4)

- O contato permite alcançar os objetivos, tais como os de orientar e implicar a família no tratamento:

É um caráter informativo mesmo do que são as dificuldades emocionais, como a família pode ajudar, de que o paciente não está naquela situação porque quer. Isso ajuda muito no ambiente familiar, também dele, e isso ajuda no tratamento. (R3)

\section{Necessidade de cuidar da família}

Os entrevistados também percebem que a família necessita de cuidados específicos, voltados tanto para a construção de formas de lidar com a doença quanto para as dificuldades emocionais, presentes entre os seus membros. Os entrevistados apresentam algumas razões pelas quais as famílias necessitam de cuidados:

- Devido à sua importância na vida do paciente e às características de sua dinâmica e história relacional. Por isso, é preciso orientá-la:

Com certeza... é o sistema... fica mais complicado quando você trabalha só com o paciente porque tem toda aquela dinâmica familiar que está adoecida. (P2)

A mãe... os pais, eu acho que eles ficaram muito desorientados, eles tinham uma necessidade muito forte de negar, mesmo quando o garoto estava internado aqui, porque o garoto fazia uso de drogas, e eles começaram a querer dizer que aquilo tudo era por causa das drogas, e eu, assim, fui muito enfática e foram várias vezes. Tive que sentar com o pai e com a mãe. (R1)

- Porque as famílias são multiproblemáticas:
Sim. Porque se a gente olhar dentro dessa perspectiva do todo, você vê a família toda, você vê que vem aquela famosa história da ponta do iceberg. Vem o paciente para você e, quando vai ver, tem várias coisas ali daquela família que não estão funcionando legal, que não estão fluindo. (P1)

- Devido à quebra das expectativas quanto ao futuro do filho, que adoeceu:

Tem dificuldade de a mãe admitir que o filho dela tenha esquizofrenia. Acho que os pais colocam, o que é totalmente normal, uma expectativa nos filhos, e é muito dificil para a mãe admitir que o filho tem uma doença grave. Eu acho que os pais precisam de muito suporte. (R2)

\section{Encaminhamentos realizados}

Diante da necessidade de oferecer um cuidado específico para as famílias, os entrevistados informam sobre os encaminhamentos que costumam realizar para terapia de família ou para algum outro tipo de atendimento.

- Ao encaminhar para a terapia de família, o resultado nem sempre é conhecido e, por isso, é questionado. A família apresenta um alto grau de complicação, já que, geralmente, apresenta uma longa história de conflitos emocionais e relacionais, desestimulando o encaminhamento. Entretanto, a terapia pode ajudar o paciente a voltar para casa:

Outro caso, que eu encaminhei, foi um paciente que tem um pai muito agressivo. Os pais são separados. É uma família bem complicada também. O pai agride fisicamente o garoto, que tem 24 anos, e também acabaram abandonando, porque nunca dá para vir todos os familiares, ou vem só a mãe ou vem só o pai. (M2)

$\mathrm{Na}$ verdade, acho que a gente está tendo muito pouco contato com a terapia de família. (...) Acho que é dificil avaliar o resultado da terapia; lembro de um caso grave que é muito dificil falar em termos de melhora, mas o que a familia participou da terapia, pôde contribuir. Depois ela parou, mas ajudou a família a voltar a receber o paciente em casa. Lembro de outra situação em que atender uma família ajudou ao paciente a voltar para casa. (M1)

- Há uma preferência pelo encaminhamento ao grupo de familiares:

Eu acho interessante a família estar até conhecendo isso para outras famílias (no grupo), como é que outras mães se posicionam. Eu acho muito bom isso. (P3)

Eu encaminhava mais para grupos de familiares. As pessoas podem trocar experiência. Dá mais resultado do que 
encaminhar para a terapia de família. Eu tenho uma preferência. Simpatizo mais com grupo de familiares. (M3)

- Paralelamente ao grupo de familiares, há também uma preferência para encaminhamento individual:

Eu faço mais individual. Eu costumo encaminhar para o grupo de família, para a pessoa ver como é que fica para ela, mas coloco à disposição a terapia individual e ai deixo primeiramente a critério dela. (...) Tenho mães, pais, familiares que vão para o grupo e se sentem super bem no grupo, mas eu acho que eu faço mais individual. (P1)

- Costuma-se encaminhar para a terapia de família quando a família "atrapalha muito", interferindo nos atendimentos, mas a constante falta de motivação dos familiares é notada:

Eu costumo (...) quando eu percebo que a família está atrapalhando muito... eu acho que é importante essa família ser encaminhada para o pessoal da especialização [de terapia de família]. (P2)

Parece que a família não tem muita motivação. Pelo menos, na maioria dos casos, não consegui que a família desse um suporte maior para o paciente. (R5)

\section{Conclusão}

No curso e tratamento da doença psiquiátrica, a família do paciente, na maioria das vezes, sofre pela ausência de dispositivos de cuidado e de atenção por parte dos inúmeros profissionais de saúde mental. Fomos surpreendidas ao identificar o esforço dos profissionais entrevistados para se aproximarem e trabalharem com as famílias dos pacientes que atendem. As formas de contato com a família são mais numerosas do que podíamos imaginar. É comum, na rotina da instituição, o profissional, mais ligado ao paciente, fornecer à família algumas informações e algumas indicações que funcionam como um suporte para os familiares, durante o tratamento. $\mathrm{O}$ contato pode persistir como uma conversa ocasional, ao mesmo tempo intensa e informal, ou pode chegar a incluir a terapia de família. Entre um ponto e o outro, existem inúmeras possibilidades de contato.

Há, porém, uma lacuna, que não tem sido preenchida, no campo dos serviços de saúde mental. Essa lacuna pode ser compreendida ao se conhecerem os conflitos entre o paciente e sua família, o preconceito dos profissionais e a falta de formação profissional. A partir dessa compreensão, pode-se montar um serviço de atendimento às famílias. Os obstáculos, para tal montagem, são também relacionados aos fatores da organização do serviço. Assim, apesar de estar previsto o atendimento, tal como preconiza a reforma psiquiátrica, se não se criam dispositivos de cuidados específicos, a família sofre pela ausência de assistência. Nesse sentido, a análise dos dados permite a identificação de quatro áreas temáticas, a serem discutidas futuramente:

1) Despreparo e sobrecarga da família, que podem ser trabalhados desde o primeiro contato com a instituição;

2) Diversificação dos cuidados oferecidos à família, adequando-os a cada caso, em vez de manter uma opção única, tal como a indicação para a terapia de família;

3) Sistematização de um trabalho de informação para as famílias, de acordo com a especificidade de cada caso, o que pode diminuir o despreparo e a sobrecarga;

4) Desenvolvimento de estratégias para a maior participação da família, visando à construção de uma aliança com a instituição psiquiátrica, ao mesmo tempo em que se cuida dos familiares.

Antes de se afirmar que o atendimento à família tem sido eficiente ou não, é preciso insistir na pergunta sobre que tipo de contato costuma ser feito com as famílias. Não há um modelo único a ser seguido. Existem modelos a serem pensados e elaborados, a partir do cotidiano e da experiência dos profissionais envolvidos. A identificação das temáticas, acima descritas, permite vislumbrar caminhos possíveis para a construção de um serviço sistematizado e que, posteriormente, poderá ser investigado quanto à sua eficácia. Assim, os objetivos, citados pelos entrevistados, podem ser implementados e os resultados alcançados podem ser discutidos.

Cuidar da família é um importante recurso para que o paciente receba alta hospitalar. Afinal, o tratamento continua no meio onde vive esse paciente, incluindo o ambiente familiar. Os parentes que cuidam do paciente psiquiátrico estão sujeitos à alta carga de estresse, sofrendo influência em sua saúde, o que pode gerar demanda por tratamentos. O impacto sofrido pode ser atenuado pelas intervenções terapêuticas, pela rede de suporte social e pelo apoio comunitário. Isso diminui o peso do contato com os serviços de saúde, ajudando os familiares na interação e na gestão da vida cotidiana dos pacientes, fortalecendo a parceria família-instituição. Assim, os fatores de estresse podem diminuir e a qualidade de vida das pessoas envolvidas pode melhorar.

De fato, a família tem importante papel no ato da internação do paciente; atua no tratamento, na recuperação e no momento da alta, mas esse papel pode ganhar maior valor. Diante da necessidade de participação no tratamento, há que se intervir no meio onde o paciente vive, desenvolvendo estratégias para que a família participe ao mesmo tempo em que se dirige, a ela, um olhar de atenção e cuidado.

Os profissionais entrevistados mantêm contatos com a família, apesar de todos os obstáculos que encontram em seu caminho. Quando se veem limitados, há uma tendência de encaminhar, para a terapia de família, aquelas famílias que trazem maior intensidade emocional e/ou apresentam mais conflitos. Ainda assim, questiona-se a eficiência dessa abordagem. O encaminhamento, por consequência, parece ser mais uma necessidade premente, diante de uma situação insustentável do que a indicação de uma abordagem específica, que articula transtorno mental e relação familiar/social. 
A sistematização e o registro dos atendimentos, evidenciando a presença da família na instituição psiquiátrica, tornam viável a realização de pesquisas que permitam demonstrar a efetividade e a eficácia das propostas de intervenção, desde os contatos informais até a terapia de família. Desse modo, um campo, que privilegia a relação interpessoal para a compreensão da saúde e da doença mental, pode ser fortalecido. Discutindo as barreiras, as vantagens e os objetivos do contato com a família, pode-se elaborar uma rotina, em que tais contatos deixam de ser mais uma fonte de estresse para todos os envolvidos e se tornam um importante recurso na assistência ao paciente psiquiátrico. Além disso, a própria família pode necessitar de cuidados específicos e os primeiros profissionais a lidarem com ela estarão preparados para fazerem os encaminhamentos pertinentes, conforme a presença de espaços diferenciados para a escuta dos familiares. Há, enfim, um longo percurso para a sistematização de um serviço voltado para a família do paciente psiquiátrico. Isso começa a ser construído ao olharmos para as diversas formas de contato que ocorrem no cotidiano da instituição psiquiátrica.

\section{Agradecimentos}

À FAPERJ, agradecemos pela bolsa de pesquisador associado concedida a Edna Ponciano, durante os anos de 2005 e 2006, para a realização desta pesquisa.

\section{Referências}

1. Féres-Carneiro T. Família: diagnóstico e terapia. Rio de Janeiro: Zahar; 1983.

2. Wittezaele JJ, Garcia T. La Escuela de Palo Alto: historia y evolución de las ideas esenciales. Barcelona: Herder; 1994.
3. Laing RD, Esterson A. Sanity, madness and the family: families of schizophrenics. 2nd ed. Londres: Tavistock; 1964.

4. Fadden G. Research update: psychoeducational family interventions. J Fam Ther. 1998;20(3):293-309.

5. Goldstein MJ, Miklowitz DJ. The effectiveness of psychoeducational family therapy in the treatment of schizophrenic disorders. J Marit Fam Therapy. 1995;21(4):361-75.

6. McFarlane WR, Lukens E, Link B, Dushay R, Deakins SA, Newmark M, et al. Multiple-family groups and psychoeducation in the treatment of schizophrenia. Arch Gener Psychiatry. 1995;52(8):679-87.

7. Moltz DA. From three languages to one: integrating individual, family and biological perspectives in the treatment of affective disorders. In: McDaniel S, Lusterman DD, Philpot CL, orgs. Casebook for integrating family therapy: an ecosystemic approach. Washington: APA; 2001.p. 349-58.

8. Nichols MP, Schwartz RC. Terapia familiar: conceitos e métodos. Porto Alegre: Artmed; 1998

9. Simoneau TL, Miklowitz DJ. Integrating psychiatry into healthy family functioning: the family psychoeducational treatment of patient with bipolar disorder. In: McDaniel S, Lusterman DD, Philpot CL, org. Casebook for integrating family therapy: an ecosystemic approach. Washington: APA; 2001. p. 359-72.

10. Uehara T, Kawashima Y, Goto M, Tasaki SI, Someya T. Psychoeducation for the families of patients with eating disorders and changes in expressed emotion: a preliminary study. Compr Psychiatry. 2001;42(2):132-8.

11. Ponciano ELT. História da terapia de família: de Palo Alto ao Rio de Janeiro [dissertação]. Rio de Janeiro: PUC-RJ; 1999.

12. Amarante P. Loucos pela vida: a trajetória da Reforma Psiquiátrica no Brasil. Rio de Janeiro: FIOCRUZ; 1995.

13. Melman J. Família e doença mental: repensando a relação entre profissionais de saúde e familiares. São Paulo: Escrituras; 2001.

14. Rosa LC. Transtorno mental e o cuidado na família. São Paulo: Cortez; 2003.

15. Pinsof WM, Wynne LC. The effectiveness and efficacy of marital and family therapy: introduction to the special issue. J Mar Fam Therapy. 1995;21(4):341-2.

16. Beach S, Kaslow N. Relational disorders and relational processes in diagnostic practice: introduction to the special section. J Fam Psychol. 2006;20(3):353-5.

17. Beach SR, Wamboldt MZ, Kaslow NJ, Heyman RE, Reiss D. Describing relationship problems in DSM-V: toward better guidance for research and clinical practice. J Fam Psychol. 2006;20(3):359-68.

18. Bandeira M, Barroso SM. Sobrecarga das famílias de pacientes psiquiátricos. J Bras Psiquiatr. 2005;54(1):34-46.

19. Vane JR, Demaria T. The psychologist as general family practitioner. Profes Psychol Res Pract. 1988;19(1):118-20.

20. Heru AM, Drury L. Overcoming barriers in working with families. Acad Psychiatry. 2006;30(5):379-84.

21. Lucksted A, Dixon L. Quality of care in services to family members of people with serious mental illnesses. Ment Healt Serv Res. 1999;1(4):223-30.

22. Bardin L. Análise de conteúdo. Lisboa: Martins Fontes; 1979. 